\title{
Meckel's diverticulum: misdiagnosis and late presentation
}

This article was published in the following Dove Press journal:

Pediatric Health, Medicine and Therapeutics

7 May 2013

Number of times this article has been viewed

\author{
Asma Mian' \\ Nasir Butt ${ }^{\prime}$ \\ Frederic Bertino' \\ Erik Shipley' \\ R Shane Tubbs ${ }^{2}$ \\ Marios Loukas' \\ 'Department of Anatomical Sciences, \\ School of Medicine, St George's \\ University, Grenada, West Indies; \\ 2Pediatric Neurosurgery, Children's \\ Hospital, Birmingham, AL, USA
}

\begin{abstract}
Meckel's diverticulum (MD) is a congenital anomaly of the gastrointestinal (GI) tract, occurring due to the incomplete obliteration of the omphalomesenteric duct during embryogenesis. Depending on the patient's age and symptomatology at presentation, scintigraphy is often the initial test of choice to detect MD. However, an increased incidence of false positive and negative tests has made MD difficult to diagnose in older children as well as in adults. MD can present in the older population with symptoms such as GI bleeding and anemia, which may mimic other GI pathologies, such as appendicitis, Crohn's disease, and Littré's hernia. Early diagnosis and appropriate management of symptomatic diverticula are vital to the prevention of complications, such as malignancy. The management of symptomatic MD is accomplished through diverticulectomy. Robijn et al proposed a scoring system based on the evaluation of the risk of complications of a nonresected MD against the complications that arise from resection. They suggested that patients with an asymptomatic MD and a risk score $<6$ should be left alone, while a risk score $>6$ indicates the need for resection. The aim of this study was to provide a review of the literature on $\mathrm{MD}$, with an emphasis on the late presentation and misdiagnosis of this congenital anomaly.
\end{abstract}

Keywords: congenital anomaly, omphalomesenteric duct, vitelline duct, GI bleeding, appendicitis, Crohn's disease

\section{Introduction to the characterization and prevalence of Meckel's diverticulum}

First described by Fabricus Hildanus in 1598, Meckel's diverticulum (MD) is the most common congenital anomaly of the gastrointestinal (GI) tract. ${ }^{1}$ It is formed due to the incomplete obliteration of the omphalomesenteric duct during early gestation and is often described by the "rule of twos."

Based on the patient's age and symptomatology, the primary method of detecting MD is through the use of technetium-99m-pertechnetate (99mTc-pertechnetate) scintigraphy, followed by exploratory laparoscopy for confirmation. However, false test results continue to be a problem, and other imaging modalities such as computed tomography (CT) have been employed in situations where scintigraphy has failed to be diagnostic. ${ }^{1,3,4}$

MD often remains asymptomatic and can present later in life, masquerading as other GI pathologies such as appendicitis, Crohn's disease, or Littré's hernia; ${ }^{5-10}$ herein lies the potential for misdiagnosis. Other symptoms and complications may also arise due to MD, such as GI bleeding, inverted MD, iron deficiency anemia, and malignancy. ${ }^{11-14}$
Deprespondence: Marios Loukas St George's University, School of Medicine, Grenada, West Indies Tel +473444 4 I 75 ext 2005

Fax +4734442887

Email mloukas@sgu.edu submit your manuscript | www.dovepress.com

Dovepress

http://dx.doi.org// 0.2147/PHMT.S31055 
The management of MD remains controversial. While the resection of symptomatic diverticula is generally agreed upon, the management of MD that is not symptomatic remains debatable. Some studies suggest that asymptomatic diverticula should be left alone, as the chance they will become symptomatic in the future is relatively low. ${ }^{15}$ However, other studies have recommended preventive diverticulectomies. ${ }^{1,15}$

Diverticulectomy is commonly performed via laparoscopy alone, or laparoscopic-assisted procedures. ${ }^{16,17}$ The greatest advantage of a laparoscopic-assisted procedure is the ability to perform an extracorporeal resection, which allows for palpation of the MD for ectopic tissue. This increases the likelihood of resecting all of the ectopic tissue and reduces the need for a subsequent procedure. ${ }^{18}$

The aim of this study is to provide a review of the literature on MD, with an emphasis on late presentation and misdiagnosis of this congenital anomaly.

\section{History}

The earliest description of this congenital anomaly was made in 1598 by Fabricius Hildanus. ${ }^{1,16,19}$ Nearly a century later, one of the first cases of the diverticulum in the terminal ileum was recorded by the German surgeon, Lavater, in $1671 .^{20}$ This outpouching of the small intestine was later illustrated in detail by Ruysch of Leyden, in 1707. ${ }^{1,20}$ Several decades later, Morgagni described the diverticulum in the duodenum, ileum, and the rectum. His descriptions included the developmental anatomy of the diverticula in the ileum, and he made connections between this developmental process and disease occurrence. ${ }^{1,20}$

It wasn't until the early 1800 s that Johann Friedrich Meckel made his contributions to our current understanding of the development of the diverticulum. Meckel described the clinical picture and the embryological features of this congenital anomaly in 1809 , giving rise to its present name. ${ }^{1,16}$ He examined 22 pediatric cadavers and described the various stages of malformations such as the omphalomesenteric cyst, omphalomesenteric fistula, umbilical sinus, and mesodiverticular band. More importantly, Meckel connected these malformations to the incomplete obliteration of the omphalomesenteric duct. ${ }^{1}$

Meckel's contributions were followed by a treatise he wrote on normal and pathological anatomy and his translation of Casper Fredrich Wolff's monograph, Ueber die Bildung des Darmkanals in Bebrüteten (About the Formation of the Intestinal Canal in Embryos), which described the development of the intestine in a chick. ${ }^{16} \mathrm{He}$ also wrote treatises on the diverticulum in 1809 , in which he reviewed the existing literature and described the development and anatomy of diverticula persisting in the terminal ileum, and connected pathologies to this developmental process. ${ }^{1,20}$ Ultimately, Meckel illustrated this intestinal diverticulum in his "Tabulae anatomico-pathologicae."21

\section{Prevalence, anatomy, and embryology Prevalence and anatomy}

MD is often described in text books for medical students by using the "rule of twos." This rule simplifies the prevalence and anatomy of $\mathrm{MD}$, as occurring in $2 \%$ of the population; twice as common in males; in individuals less than 2 years old; and usually protruding from the ileum approximately 2 feet from the ileocecal valve. ${ }^{2}$ While this rule is convenient, Moore et al reported ${ }^{22}$ that, in fact, MD occurs in $2 \%-4 \%$ of infants; is three to five times more prevalent in males than in females; is usually $3-6 \mathrm{~cm}$ long; and is observed as a finger-like pouch arising from the antimesenteric border of the ileum, about 40 to 50 centimeters proximal to the ileocecal junction. The average size of the diverticulum is $2.9 \mathrm{~cm}$ long and $1.9 \mathrm{~cm}$ wide; ${ }^{1}$ however, Limas et $\mathrm{a}^{23}$ have reported "giant" MD, with dimensions as large as $16 \mathrm{~cm}$ long and $4 \mathrm{~cm}$ wide.

\section{Embryology}

The extraembryonic membrane, known as the yolk sac, is seen by the fourth week of gestation. At this time, the yolk sac becomes host to the formation of the neural tube, as somites rapidly develop over its caudal rim. ${ }^{1}$ The yolk sac narrows as the body of the embryo folds and the ectodermal, mesodermal, and endodermal layers form. The GI tract arises from the endoderm and forms the foregut, hindgut, and midgut. Initially, the midgut remains open to the yolk sac, but, as development progresses, the yolk sac narrows further and reduces communication with the midgut. The yolk sac eventually reduces to a slim stalk, which is known as the omphalomesenteric duct, the vitelline duct, or simply as the yolk stalk. ${ }^{24}$ Nutrients are transported between the yolk sac and the developing embryo through the yolk stalk. ${ }^{1}$ By the sixth week of gestation, the yolk stalk and sac disappear along with the vitelline arteries. ${ }^{1}$

Failure of the vitelline duct to regress may result in a variety of congenital anomalies (Figure 1). The classic MD is a finger-like outpouching of the ileal wall. An omphalomesenteric fistula can occur when the vitelline duct in the abdominal wall remains patent. An isolated omphalomesenteric cyst, 


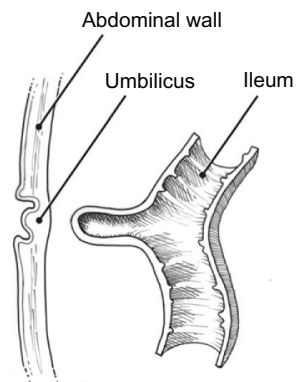

Meckel's diverticulum

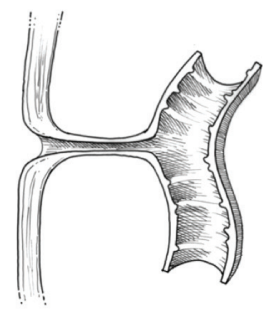

Fistula

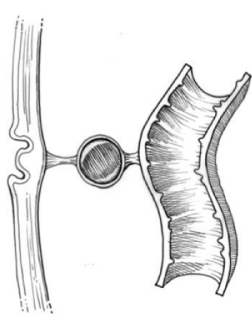

Cyst

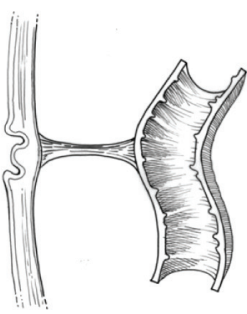

Fibrous band

Figure I Illustration of the congenital anomalies that may arise from incomplete obliteration of the vitelline duct.

Note: From left to right: Meckel's diverticulum, omphalomesenteric fistula, omphalomesenteric cyst, and omphalomesenteric ligament.

suspended by ligaments, may also form. Finally, a fibrous band, known as an omphalomesenteric ligament, may form, connecting the ileum to the abdominal wall at the level of the umbilicus. ${ }^{24}$

MD contains all three layers of the intestinal wall. It also has its own blood supply - a branch of the superior mesenteric artery, called the vitelline artery. This blood supply makes it vulnerable to infection and a candidate for obstruction, similar to the appendix..$^{1,16}$

Nearly half of all MD contain ectopic tissue. While the exact cause for this ectopic tissue is unknown, the occurrence of heterotopic gastric and pancreatic mucosa with an MD is common. ${ }^{1}$ It has been suggested that prior to the union of the anterior and posterior pancreas during development, small buds are left in the foregut and move with subsequent gut development. Other ectopic tissues such as colonic, duodenal, jejunal, hepatic, and endometrial, have also been reported in the literature; however, these cases are rare and have not been known to result in complications. ${ }^{1,20}$

\section{Detection methods and recognition of late presentation}

While MD remains mostly asymptomatic in the population, the probability of a symptomatic presentation is between $4 \%-6 \%$. This incidence has been reported to decrease with age. MD can present with a variety of symptoms ranging from intestinal obstruction, bleeding, and perforation. ${ }^{1,23}$ In a 10 -year study of the adult population with MD, Stone et $\mathrm{al}^{25}$ reported that the most common presentation was diverticulitis, followed by obstruction. Acute bleeding was the least common presentation in this group, and the most common ectopic tissue found was gastric mucosa, as one would expect.

The primary method of detecting MD is through the use of technetium $99 \mathrm{~m}$-pertechnetate (99mTc-pertechnetate) scintigraphy, followed by exploratory laparoscopy for confirmation.
In the following section, we will discuss several modalities with which MD can be identified, either directly or through the exclusion of other pathologies.

\section{$99 \mathrm{mTc}$-pertechnetate scintigraphy}

Harden was the first to propose the use of $99 \mathrm{mTc}$-pertechnetate to detect ectopic gastric mucosa in 1962. In 1970, Jewett et al recommended its usage clinically to determine the location of MD. ${ }^{1}$ While this diagnostic tool is highly effective in diagnosing children with MD, its sensitivity, specificity, and accuracy falls greatly when applied to adults, with values of $62 \%, 9 \%$, and $46 \%$, respectively. ${ }^{26,27}$ This difference may be attributed to the area of involvement of the ectopic gastric mucosa; scintigraphy detects areas with larger ectopic gastric mucosa, which are most likely to hemorrhage earlier. ${ }^{1}$

Due to the lower values of sensitivity and specificity, scinitigraphy is prone to producing false positive and negative results. False positives arise when other sites containing ectopic gastric mucosa pick up the $99 \mathrm{mTc}$-pertechnetate, as well as due to vascular anomalies, bowel ulcerations, inflammation, and obstruction. ${ }^{3}$ False negatives arise when the ectopic gastric tissue in the diverticulum is very minimal or when the scintigraphic activity is diluted due to bowel hypersecretion or sudden hemorrhage. ${ }^{1,3}$ The accuracy of scintigraphy may be increased by several methods that will be discussed later.

Scintigraphy is often the initial diagnostic test performed to detect MD, due to its noninvasive and relatively expedient nature, as opposed to laparoscopic exploration, which is invasive and requires significantly more time and resources. Still, the use of $99 \mathrm{mTc}$-pertechnetate in cases of profuse intestinal bleeding has been questioned due to its lack of accuracy and difficult implementation in emergency situations. ${ }^{5}$ In addition, a negative scan warrants the need for intestinal exploration. Another deficit of $99 \mathrm{mTc}$-pertechnetate is that 
it cannot detect specific complications of an MD, such as Meckel's diverticulitis or Meckel's diverticular bands. ${ }^{5}$

\section{Computed tomography and ultrasound}

If an initial 99mTc-pertechnetate scan is nondiagnostic and acute bleeding has been ruled out, computed tomography and ultrasonography can be used to detect an inflamed MD in a noninvasive manner (Figure 2). ${ }^{1,4} \mathrm{CT}$ scans have been shown to be useful for diagnosing intestinal obstruction and are an excellent tool in situations where diagnostic laparoscopy is contraindicated. Ultrasound has been used to visualize Meckel's diverticulitis, which appears similar to appendicitis and produces wall hyperemia on a color Doppler. ${ }^{4}$

\section{Laparoscopy}

Many practitioners favor laparoscopy for diagnosis of MD because of its ability to delineate common manifestations of MD as well as those less common, such as torsion. ${ }^{5}$ Chu et $\mathrm{al}^{28}$ studied the use of laparoscopy for diagnosis and treatment of patients with MD. They supported laparoscopy as a valuable method for the diagnosis of MD, providing accuracy of results while remaining a minimally invasive technique. As noted earlier, accuracy is important as MD can manifest in a variety of ways: short or long, with or without ectopic tissue, and possibly with an ulcerated ileum. Taking this into consideration, Chu et al suggested that, at least for symptoms of abdominal pain and GI bleeding, laparoscopic management is superior to other methods of diagnosis. They did not, however, recommend it for patients presenting with
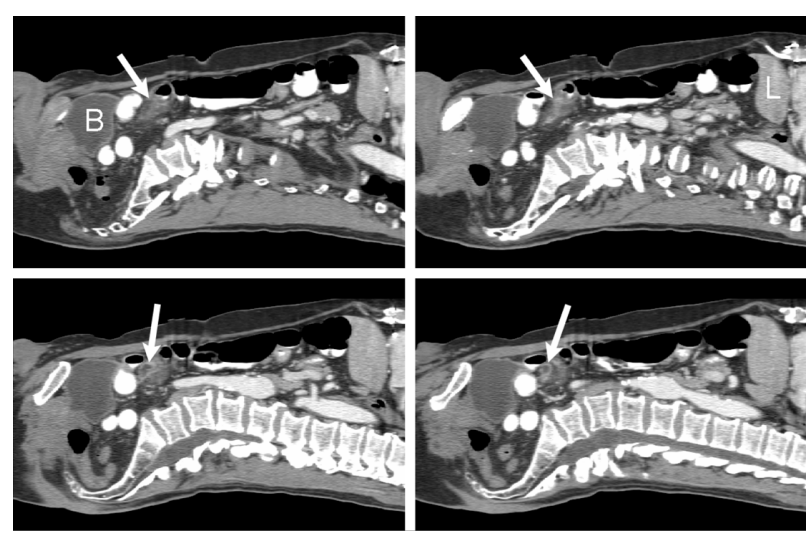

Figure 2 A sagittally reconstructed abdominal CT scan of a 75-year-old male with vague abdominal pain.

Notes: There is diffuse, mild small bowel dilatation and a fluid-filled projection from a pelvic small bowel loop, with an enhancing wall and evidence of inflammation (arrows). This is similar in appearance to an inflamed appendix; however, the location is more consistent with Meckel's diverticulum, which was found at laparotomy.

Reproduced with permission from Uppal K, Tubbs RS, Matusz P, Shaffer K, Loukas M. Meckel's diverticulum: a review. Clin Anat. 20I I;24(4):416-422.'

Abbreviations: B, bladder; CT, computed tomography; L, liver. symptoms of obstruction where it would be difficult to inflate the abdominal cavity, which is a necessary step for proper visualization of abdominal contents. ${ }^{28}$

On the other hand, Fagenholz and de Moya reported a successful case of laparoscopic identification and treatment of obstruction of the small bowel due to an MD. ${ }^{29}$ The authors did not mention why their procedure worked despite opposing contentions held in the literature, but perhaps it was due to the fact that the obstruction required merely the resection of the MD and the phytobezoar within it. This procedure was similar to laparoscopy-assisted diverticulectomy. Thus, peritoneal inflation may have been easier to establish in this procedure than in other procedures for GI obstruction. ${ }^{29}$

\section{Angiography and colonoscopy}

These techniques have been shown to be useful in specific situations. Practitioners have been able to identify active bleeding by angiography or CT angiography. ${ }^{30}$ The small intestine accounts for 5\% of GI bleeding. ${ }^{31}$

\section{Misdiagnosis and unusual findings in MD diagnosis: a review of case reports}

MD can present in patients with a wide variety of symptoms that may mimic those of other acute and chronic GI pathologies. These presentations often steer the diagnostic process off course and interfere with appropriate treatment protocols.

\section{Appendicitis}

Perforation is a rare complication of MD. However, when it does occur, it presents in a manner similar to acute appendicitis. Due to the emergent nature of acute appendicitis, MD pathology is often not diagnosed until surgery. It is recommended that proper imaging studies for MD, such as ultrasound and CT, be performed prior to a more invasive approach if the patient is not in acute distress and does not require immediate surgery for acute appendicitis. ${ }^{1}$

MD is misdiagnosed as appendicitis on ultrasound imaging in approximately $11 \%$ of all MD cases. ${ }^{5,6}$ The presentation of patients with a perforated MD mimics that of patients presenting with acute appendicitis. The perforation is usually caused by ingested material such as wood splinters and fish bones. ${ }^{32,33}$ However, mucosal trauma and tumors, such as leiomyosarcoma, within the MD have also been observed to cause perforation. ${ }^{11,34-37}$

Canelas et al reported a case in which a 52-year-old man with a perforated MD presented with right lower quadrant 
abdominal pain, nausea, vomiting, and intermittent fever. ${ }^{33}$ Similarly, A 12-year-old boy arrived at the emergency department with the sole symptom of severe periumbilical pain and was suspected to have a ruptured appendix. ${ }^{6}$

In 2011, Karabulut et $\mathrm{al}^{38}$ found that out of 47 patients admitted for acute appendicitis that was negative upon exploratory laparoscopy, 13 were identified as cases of MD. This was the second most common diagnosis in this group, next to mesenteric lymphadenitis (Table 1).

\section{Crohn's disease}

MD perforation can mimic a variety of pathological conditions. Bondeson and Starck-Bondeson ${ }^{8}$ suggested that MD is a common finding among patients with terminal ileal Crohn's disease; however, the etiology of this is unknown. Wong et $\mathrm{al}^{11}$ described a tall, thin, 21-year-old male with worsening constipation and increased flatus. The patient had a positive family history of Crohn's disease and reported a $10 \mathrm{~kg}$ weight loss, anorexia, decreased stool caliber, and dysuria. Diagnostic studies showed ileal thickening, ileocecal fistula, and a pelvic abscess, all thought to be due to Crohn's. However, exploratory surgery revealed a perforated MD adherent to an inflamed and fibrotic ileocecal fistula. ${ }^{11}$ While MD masquerading as Crohn's disease is relatively rare, it is not uncommon to find the presence of MD in patients with Crohn's.

Similarly, Enc et $\mathrm{al}^{39}$ described a 19 -year-old female who presented with severe postprandial periumbilical pain for 1 year, anorexia, and a $10 \mathrm{~kg}$ weight loss. Enteroclysis revealed a $3 \mathrm{~cm} \times 15 \mathrm{~cm}$ diverticular mass in the pericecal region, and the patient was treated for Crohn's disease. Conservative treatment failed, and the patient underwent an ileal resection, upon which a perforated MD was noted in addition to an ulcerated ileum. It is important to note that MD does not commonly present with anorexia, anemia, and ileocecal ulceration; however, MD should be considered in

Table I Positive intraoperative findings of negative appendectomies in 47 patients

\begin{tabular}{ll}
\hline Diagnosis & Number of patients (\%) \\
\hline Mesenteric lymphadenitis & $23(15)$ \\
Meckel's diverticulum complications & $13(8.7)$ \\
Ovarian cysts & $4(2.6)$ \\
Ovarian torsion & $2(1.3)$ \\
Omental infarction & $2(1.3)$ \\
Tubo-ovarian abscess & $\mathrm{I}(0.6)$ \\
Mesocyst & $\mathrm{I}(0.6)$ \\
Acute pancreatitis & $\mathrm{I}(0.6)$ \\
\hline
\end{tabular}

Reproduced with permission from Karabulut R, Sonmez K, Turkyilmaz Z, et al Negative appendectomy experience in children. Ir J Med Sci. 20I I; I80(I):55-58. ${ }^{38}$ the differential for Crohn's disease when these symptoms are present. ${ }^{39}$

In a study examining patients undergoing hemicolectomy for Crohn's disease, Andreyev et $\mathrm{al}^{7}$ found that approximately $6 \%$ of patients between the ages of 18 and 56 years had MD with terminal ileal inflammation close to the mouth of the diverticulum. Only $41 \%$ of these diverticula were examined histologically. and none of the specimens showed evidence of heterotopic tissue. One patient had tested positive for MD preoperatively; however, this was considered to be a false positive due to the presence of Crohn's.

Based on the findings from their study, Andreyev et $\mathrm{al}^{7}$ concluded that the prevalence of MD is three times higher in patients with Crohn's disease than in the general population. While heterotopic gastric mucosa may cause terminal ileal inflammation, this is rarely seen as the cause of inflammation in these patients, either due to low symptom prevalence or milder presentations, which do not require surgical intervention. Thus, the authors rejected the notion that gastric mucosa in MD causes terminal ileitis. ${ }^{7}$

In addition to these conclusions, Andreyev et $\mathrm{al}^{7}$ proposed three possible explanations for the association between MD and Crohn's disease. Firstly, MD and Crohn's disease may be linked by a common underlying factor, explaining why they occur together in many patients. Secondly, Crohn's disease may be present for many years before it becomes clinically significant; it is unlikely, however, that Crohn's can act on patients prior to the obliteration of the vitelline duct, which promotes retention of the diverticulum. Finally, it is possible that MD predisposes patients to Crohn's disease by one of two mechanisms. One mechanism is by way of trapped infectious agents within the diverticulum that increase GI permeability; this correlates with data that suggest increased permeability is one of the early signs of Crohn's disease and a marker of increased familial risk and relapse. The second mechanism by which MD may predispose patients to Crohn's disease is through the diverticulum's role in causing disruptions in gut motility, promoting ischemia, or even preventing proper lymphatic drainage. Any of these possibilities may predispose a patient to Crohn's disease.?

\section{Littré’s hernia}

Littré's hernia refers to an incarcerated hernia that contains a small bowel diverticulum. This was first identified in 1700 by Alexis Littré. ${ }^{9,10}$ The two most common sites for this occurrence are in the inguinal and femoral regions. ${ }^{1}$ Littré's hernia presents as a painful groin mass, without evidence of obstruction or peritonitis. Wollgast and Hilz reported 
35 cases of Littré's hernia before 1954, most of which were right-sided. ${ }^{10}$ Bowel necrosis, as well as Richter's hernia (herniation of the antimesenteric border of the small bowel), were ruled out in these patients, as none of them presented with fever or tachycardia. Page et $\mathrm{al}^{9}$ reported a case of a 77-year-old woman with a history of breast carcinoma who presented with nausea and vomiting. The symptoms were attributed to recent chemotherapy; however, the patient discovered a right groin bulge following a bout of emesis, which was confirmed by $\mathrm{CT}$ to be an inguinal hernia containing a loop of small bowel. The hernia was surgically reduced, and the hernia sac contained a cystic mass consistent with MD. ${ }^{9}$ Similarly, Baum and $\mathrm{Olch}^{40}$ described a man with a left-sided groin mass, which was found to contain a gangrenous MD approximately $6 \mathrm{~cm}$ in length. Finally, a 61-year-old male presented with a right-sided lump in the groin and no other symptoms, and this was later revealed to be an MD within a femoral hernia. ${ }^{40}$

\section{Gl bleeding}

MD can often present with blood in the colon, particularly if the MD abnormality is located in an unusual location or if the ectopic tissue has caused ulceration. Ectopic gastric mucosa found in MD can often cause bleeding ulcers of the terminal ileum, from the ileocolic artery. ${ }^{12,13}$ GI bleeding associated with MD can present in fast, large volume episodes of painless, bright red blood loss, or as slow and occult blood loss with a guaiac-positive test result and, occasionally, anemia. ${ }^{13}$ GI bleeding can be explained in $62 \%-100 \%$ of cases by the ulceration of heterotopic gastric mucosa. ${ }^{41}$ However, Reddin and Rosenbaum stated that MD is an uncommon cause of GI bleeding. ${ }^{42}$

In 2011, Yang et $\mathrm{al}^{12}$ reported seven cases of MD with ectopic pancreatic tissue that occurred within the previous 30 years. These patients' ages ranged from 11-66 years (with a median age of 19.8 years). Yang et al ${ }^{12}$ stated that lower GI bleeding was more common in older patients with MD with ectopic pancreatic tissue than in those patients who suffered from ulceration of the gastric mucosa. However, the pathophysiology of the bleeding is similar to that of gastric mucosa ulceration, as the mucosal secretions are responsible for causing GI ulceration as well as bleeding. Ectopic pancreatic tissue has also been linked to adenocarcinoma in some patients. ${ }^{44}$

Oglevie et $\mathrm{al}^{13}$ reported a case of a 29 -year-old who presented with sudden onset of painless rectal bleeding. Multiple diagnostic tests were negative and failed to identify the source of the bleeding. Finally, repeat contrast studies revealed an
MD in the right upper quadrant. Histopathological studies identified ulcerated ectopic gastric mucosa within the MD as the source of bleeding. Similarly, a 69-year-old female also presented with painless rectal bleeding. ${ }^{12}$ A CT angiography was performed and detected active bleeding of the ileocolic artery. The source of bleeding was identified as an MD containing ectopic pancreatic tissue. Based on these findings, Yang et $\mathrm{al}^{12}$ suggest that $\mathrm{MD}$ be considered in adult patients presenting with massive painless GI bleeding.

\section{Inverted MD and iron-deficiency anemia}

Iron-deficiency anemia is a common finding among patients with GI bleeding and MD ulceration. ${ }^{11}$ However, there have been cases reporting inverted Meckel's diverticula in which patients present with microcytic anemia in the absence of bleeding. James et $\mathrm{al}^{45}$ described a 52 -year-old patient with an inverted MD presenting with remarkable iron deficiency, without any evidence of gross or occult bleeding. Resection of the diverticulum corrected the anemia, and the patient was subsequently symptom free. Histological studies did not reveal a source of the bleeding. Shelton et $\mathrm{al}^{46}$ presented a similar case of a 48-year-old female with iron deficiency anemia, fatigue, and abdominal bloating. CT scan of the abdomen revealed an endoluminal mass in the distal ileum. The mass was discovered to be an inverted MD containing ectopic pancreatic tissue, upon surgical resection. A source of bleeding was not found; however, the patient's anemia resolved postoperatively. ${ }^{46}$

Inverted MD does not always present in the aforementioned way. Steinwald et $\mathrm{al}^{47}$ suggested that GI bleeding is more commonly associated with right-sided MD and that an inverted MD is more likely to cause bowel obstruction. This inversion may serve as a lead point for ileo-ileal intussusception and can also simulate a pedunculated small bowel polyp. ${ }^{1}$ The anemia resulting from MD is usually secondary to a GI bleed. ${ }^{41,45,49,50}$ The etiology of anemia presenting with a nonbleeding MD remains unknown.

\section{Malignancies within MD}

The prevalence of ectopic tissue within an MD is between $10 \%-60 \%$ and usually remains asymptomatic. ${ }^{14}$ However, ectopic tissue has been associated with an increased risk of malignancy, especially pancreatic adenocarcinoma. ${ }^{7,44,51,52}$ Malignancy accounts for approximately $0.5 \%-3.2 \%$ of the complications associated with MD. The most common malignancy associated with MD is carcinoid tumor. ${ }^{53-56}$ Others include adenocarcinoma, pancreatic carcinoma, intraductal papillary mucinous neoplasm, GI stromal tumors (GIST) 
and leiomyosarcomas, lymphoma, lipoma, adenomyoma, and villous adenoma. ${ }^{44,57-69}$ Table 2 provides a comprehensive list of demographics concerning MD-related malignancy.

Anderson ${ }^{53}$ reported a case involving a 62-year-old male who presented with right upper quadrant abdominal pain, nausea, indigestion, and fatty food intolerance. Imaging studies were unremarkable, with the exception of a gallbladder ejection obstruction. Upon surgical exploration, the patient was diagnosed with MD with carcinoid tumor. ${ }^{53}$ Carcinoid tumor associated with MD is usually diagnosed after bowel resection. ${ }^{14,36,70,71}$ Moyana ${ }^{54}$ found that jejunoileal carcinoid tumors most similarly resemble the type associated with MD, on immunohistochemical analysis. The survival

Table 2 Patient characteristics of all cases of Meckel's tumors

\begin{tabular}{|c|c|c|}
\hline Patient characteristics & $\begin{array}{l}\text { Number of patients } \\
(n=I 58)\end{array}$ & $\begin{array}{l}\text { Percentage } \\
\text { (\%) }\end{array}$ \\
\hline \multicolumn{3}{|l|}{ Gender } \\
\hline Male & 101 & $64 \%$ \\
\hline Female & 57 & $36 \%$ \\
\hline \multicolumn{3}{|l|}{ Race } \\
\hline African-American & 148 & $94 \%$ \\
\hline European & 6 & $4 \%$ \\
\hline Other & 4 & $2 \%$ \\
\hline \multicolumn{3}{|c|}{ Major pathological subtypes } \\
\hline Carcinoid & 121 & $76.5 \%$ \\
\hline Adenocarcinoma & 18 & $11.4 \%$ \\
\hline $\begin{array}{l}\text { GIST/leiomyosarcoma/ } \\
\text { sarcoma }\end{array}$ & 17 & $10.8 \%$ \\
\hline Lymphoma & 2 & $1.3 \%$ \\
\hline \multicolumn{3}{|l|}{ Tumor behavior } \\
\hline Benign & 0 & $0 \%$ \\
\hline Malignant & 158 & $100 \%$ \\
\hline \multicolumn{3}{|l|}{ Tumor size } \\
\hline$<\mathrm{l} \mathrm{cm}$ & 14 & $48.3 \%$ \\
\hline $\mathrm{I}-5 \mathrm{~cm}$ & 6 & $20.7 \%$ \\
\hline$>5 \mathrm{~cm}$ & 6 & $20.7 \%$ \\
\hline Unknown & 3 & $10.3 \%$ \\
\hline \multicolumn{3}{|l|}{ Stage } \\
\hline Localized & 106 & $67.1 \%$ \\
\hline Regional (positive nodes) & 24 & $15.2 \%$ \\
\hline Metastatic & 16 & $10.1 \%$ \\
\hline Unstaged & 12 & $7.6 \%$ \\
\hline \multicolumn{3}{|l|}{ Surgical treatment } \\
\hline Performed & $15 \mid$ & $95.6 \%$ \\
\hline $\begin{array}{l}\text { Recommended but not } \\
\text { performed }\end{array}$ & 6 & $3.8 \%$ \\
\hline Not recommended & I & $0.6 \%$ \\
\hline \multicolumn{3}{|l|}{ Radiation } \\
\hline No radiation & 156 & $98.8 \%$ \\
\hline Beam radiation & 1 & $0.6 \%$ \\
\hline Unknown & I & $0.6 \%$ \\
\hline
\end{tabular}

Reproduced with permission from Thirunavukarasu P, Sathaiah M, Sukumar S, et al. Meckel's diverticulum - a high-risk region for malignancy in the ileum. Insights from a population-based epidemiological study and implications in surgical management. Ann Surg. 20I I;253(2):223-230. ${ }^{14}$

Abbreviation: GIST, gastrointestinal stromal tumors. rate for patients with locally-staged, small bowel carcinoid tumors in the absence of MD is approximately $75 \% .^{72} \mathrm{Olson}$ et $\mathrm{al}^{73}$ reported a 5 -year survival rate of $83 \%$ in patients with a combination of MD and carcinoid tumor. The 5-year survival rate declined to approximately $50 \%$ in patients with metastases.

In addition to carcinoid tumors, $12 \%$ of MD-associated tumors are GIST. ${ }^{74}$ Mitchell et al ${ }^{75}$ documented a 39-year-old male with severe abdominal pain in the right iliac fossa, with localized peritonism, fever, and tachycardia. The patient had a previous appendectomy, and after a CT scan located a small bowel obstruction, a diagnosis of tumor or MD was suggested. Khoury and Aulicino ${ }^{63}$ reported a 28-year-old male with severe abdominal pain, nausea, and vomiting. CT scan showed small bowel obstruction resembling a cystic mass. MD was the preoperative diagnosis. Chou et al ${ }^{76}$ reported a 76-year-old female with lower abdominal cramping for two days, nonbloody diarrhea, and vomiting. CT scan revealed small bowel perforation and a distended diverticulum with fluid accumulation. Laparoscopy confirmed a perforated MD. Each of these patients was diagnosed with GIST upon resection of the MD.

Similarly, Chandramohan et $\mathrm{al}^{74}$ presented a case of a 65-year-old male with constipation of 4-months duration and rectal bleeding for one month. A lobulated mass compressing the anterior wall of the sigmoid colon was found on CT examination. Exploratory laparotomy found a mass within an MD, which was later confirmed as GIST. ${ }^{74}$ Finally, Sozen and Tuna ${ }^{77}$ presented a 62 -year-old female with periumbilical pain in the right iliac fossa and localized peritonism. A palpable mass was present in the right lower quadrant, and air pockets on X-ray indicated an obstruction. Upon surgical intervention for suspected appendicitis, a perforated MD with nodular mass was found. ${ }^{77}$

Due to the nonspecific presentation of MD and associated complications, it is important to know that tumors associated with MD can present in a plethora of ways. The average age of presentation with symptomatic GIST is usually within the sixth decade. These are most commonly found in the stomach $(60 \%-70 \%)$, and fewer $(20 \%-30 \%)$ are found in the small intestine. ${ }^{63}$

\section{False test results and misdiagnosis}

Just as with atypical symptoms and presentation, MD can also be misdiagnosed due to diagnostic errors. As mentioned previously, the $99 \mathrm{mTc}$-pertechnetate scan is the initial test of choice for detecting MD but may produce misleading results, especially in the adult population. ${ }^{42,78}$ 
Summers et $\mathrm{al}^{78}$ reported a case in which a 47 -year-old male presented with bloody diarrhea, fatigue, nausea, and vomiting. A 99mTc-pertechnetate scan produced noticeable radiotracer uptake in the mid-abdomen. Although this was an unusual location for MD, it became the most likely diagnosis until laparoscopy confirmed that this was in fact, an enlarged appendix containing a carcinoid tumor. ${ }^{78}$ Similarly, Reddin and Rosenbaum ${ }^{42}$ discovered a false positive scan for MD in a 32-year-old patient presenting with rectal bleeding a carcinoid tumor was found without MD. In a similar case, Tulchinsky ${ }^{43}$ reported a patient with low-volume, intermittent small bowel bleeding who tested positive on a $99 \mathrm{mTc}-$ pertechnetate scan for MD but who was later diagnosed with a bleeding ileal ulcer without MD, by capsule endoscopy.

False negatives arise when the ectopic gastric tissue in the diverticulum is very minimal or when the scintigraphic activity is diluted due to bowel hypersecretion or sudden hemorrhage. ${ }^{1,3}$ Hod et al ${ }^{79}$ suggested that a $99 \mathrm{mTc}$-pertechnetate scan should be postponed if a barium procedure was recently performed. The accuracy of the scan can be improved if the test is repeated when the barium contrast is known to be fully cleared from the system. ${ }^{44}$ Several other methods of increasing the accuracy of scintigraphy have also been proposed: the use a of more water-soluble isotope of technetium may increase uptake; histamine blockers may be used to inhibit pertechnetate secretion after uptake; and glucagon has been shown to prevent wash-out of the pertechnetate by peristalsis. ${ }^{1,20}$

\section{Treatment and prognosis}

The management of MD is controversial, especially pertaining to diverticula that remain asymptomatic. According to some studies, the rate of complications arising from surgical removal of the diverticulum is approximately $1 \%$, with a $5 \%-6 \%$ lifetime risk of complications, such as peritonitis. ${ }^{1}$ Other studies suggest that asymptomatic MD should be left alone, while symptomatic diverticula should be removed at any time up to the age of 80 years. ${ }^{15}$

Artigas et al ${ }^{80}$ conducted a 15 -year retrospective study and concluded that asymptomatic MD should not be resected due to the likelihood that the diverticulum would not become symptomatic in the future. They also noted that the chance of the diverticulum becoming symptomatic decreased with age. ${ }^{1,80}$ However, other studies have recommended preventive diverticulectomy. An epidemiological study performed at the Mayo Clinic looked at 50 years' worth of data and concluded that all incidentally discovered diverticula should be resected at any age. ${ }^{1,15}$
Robijn et a ${ }^{81}$ proposed a scoring system based on the risk of complications of a nonresected MD against the complications that arise from resection. They identified the most common risk factors for asymptomatic diverticula, which increase the risk of future complications. A Risk Score was created, based on the following four risk factors: male gender, young age ( $<45$ years), diverticula length $>2 \mathrm{~cm}$, and presence of a fibrous band (Table 3) ${ }^{81}$ The presence of ectopic tissue in the diverticulum has been associated with an increased risk of bleeding and ulceration but was not included in the Risk Score proposed by Robijn et al. They suggested that patients with an asymptomatic MD and a risk score $<6$ should be left alone, while a risk score $>6$ indicates the need for resection.

The goal of a Meckel's diverticulectomy is to resect the entire diverticulum along with ectopic gastric tissue, pancreatic epithelium, or peptic ulcers of the nearby ileum. ${ }^{5}$ This procedure is usually performed using laparoscopic surgery or laparoscopy-assisted surgery.

\section{Laparoscopic surgical intervention}

The goal of laparoscopic surgical intervention for a Meckel diverticulectomy is to introduce a laparoscope and conduct an intracorporeal resection of the MD, all ectopic tissue, and any ulceration in the ileum. ${ }^{17}$ If the base is narrow and has no mass in the ileum, then procedure calls for a simple wedge resection of the diverticulum and a transverse closure of the ileum, using a linear stapler. If the base is too wide or the patient has palpable ectopic tissue or inflammation, the involved bowel should be resected as well. Assuming this

Table 3 Risk Score proposed by Robijn et al, to determine the need for resection in patients with asymptomatic Meckel's diverticula

\begin{tabular}{ll}
\hline Risk factor & Points \\
\hline Gender & 3 \\
Male & $\mathrm{I}$ \\
Female & \\
Age & 2 \\
$<45$ years & $\mathrm{I}$ \\
$\geq 45$ years & \\
Length of diverticulum & 2 \\
$<2 \mathrm{~cm}$ & $\mathrm{I}$ \\
$\geq 2 \mathrm{~cm}$ & \\
Presence of fibrous band & 3 \\
Yes & 0 \\
No & Total points \\
Risk score &
\end{tabular}

Reproduced with permission from Robijn J, Sebrechts E, Miserez M. Management of incidentally found Meckel's diverticulum a new approach: resection based on a Risk Score. Acta Chir Belg. 2006; 106(4):467-470.81 
wide MD is in the ileum, an ileoileostomy would then be performed to reconnect the separated parts of the ileum. ${ }^{17}$

The use of laparoscopy for MD has been debated due to the risk of recurrence if any ectopic tissue is left behind. Upon examination of the external appearance of the diverticulum, some have concluded that a simple transverse resection can be done for long diverticula, as these will have their ectopic gastric tissue at the distal end. ${ }^{82}$ However, in short diverticula, the ectopic tissue can exist in nearly any area and should be removed through an ileal resection with end-to-end anastomosis or through a wedge resection done after exteriorization, in order to ensure the removal of all ectopic tissue and avoid future complications necessitating a second surgery. ${ }^{82}$

Mukai et al, ${ }^{82}$ among others, have set measurable guidelines defining MD as long or short. These guidelines have been based on the knowledge that heterotopic tissue will grow from the pleuripotent yolk sac, at the distal end of a MD. Varcoe et $\mathrm{a}^{83}$ believe that a height to diameter ratio $>2$ indicates a long MD and should be resected using a simple transverse approach, whereas a value $<2$ indicates a short MD. They suggested that an MD should be resected via an ileal resection with end-to-end anastomosis. ${ }^{83}$ Mukai et a ${ }^{82}$ believe a height to diameter ratio $>1.6$ indicates the presence of heterotopic gastric epithelium in the distal end of the diverticulum, whereas a height to diameter ratio value $<1.6$ indicates a clinically significant risk of having epithelium in nearly all areas of the diverticulum.

\section{Laparoscopic-assisted transumbilical Meckel's diverticulectomy (LATUM)}

LATUM involves fewer incisions than traditional laparoscopic surgery. An incision is made at the umbilicus, into which the laparoscope is introduced with a trocar. ${ }^{16}$ The laparoscope is then used to bring the MD out through the incision. In this way, the base of the diverticulum may be palpated for ectopic tissue, greatly diminishing the risk of residual tissue being left in the ileum and decreasing the need for a subsequent surgical procedure. ${ }^{16}$ Thus, the greatest advantage of LATUM is the ability to perform an extracorporeal resection, which allows for palpation of the MD and greater success at detecting ectopic tissue than does the laparoscopic technique on its own, as well as remaining less invasive than an open procedure. ${ }^{18}$

\section{Conclusion and future directions}

$\mathrm{MD}$ is the most common congenital anomaly of the GI system. Despite this, it is often asymptomatic and therefore, left undetected until later in life. This diverticulum can present in a myriad of ways, often mimicking appendicitis, and is easily misdiagnosed. Left undiagnosed, significant GI distress can result, including an increased potential for GI bleeding, nonhemorrhagic iron deficiency anemia, and many types of GI cancer.

The key to prevention of complications is early diagnosis and treatment. While treatment of asymptomatic diverticula remains debatable, untreated symptomatic MD can have dire consequences. Thus, it is important for clinicians to include $\mathrm{MD}$ as a possible differential diagnosis, when presented with older patients displaying nonspecific GI symptoms.

\section{Disclosure}

The authors declare that they had no conflicts of interest in this work.

\section{References}

1. Uppal K, Tubbs RS, Matusz P, Shaffer K, Loukas M. Meckel's diverticulum: a review. Clin Anat. 2011;24(4):416-422.

2. Yamaguchi M, Takeuchi S, Awazu S. Meckel diverticulum. Investigation of 600 patients in Japanese literature. Am J Surg. 1978;136(2):247-249.

3. Connolly LP, Treves ST, Bozorgi F, O’Conner SC. Meckel's diverticulum: demonstration of heterotopic gastric mucosa with technetium99m-pertechnetate SPECT. J Nucl Med. 1998;39(8):1458-1460.

4. Baldisserotto M. Color Doppler sonographic findings of inflamed and perforated Meckel's diverticulum. J Ultrasound Med. 2004; 23(6):843-848.

5. Sai Prasad TR, Chui CH, Singaporewalla FR, et al. Meckel's diverticular complications in children: is laparoscopy the order of the day? Pediatr Surg Int. 2007;23(2):141-147.

6. Kloss BT, Broton CE, Sullivan AM. Perforated Meckel diverticulum. Int J Emerg Med. 2010;3(4):455-457.

7. Andreyev HJ, Owen RA, Thompson I, Forbes A. Association between Meckel's diverticulum and Crohn's disease: a retrospective review. Gut. 1994;35(6):788-790.

8. Bondeson L, Starck-Bondeson AG. Crohn's disease in heterotopic gastric mucosa in a Meckel's diverticulum. Acta Pathol Microbiol Scand A. 1974;82(3):427-430.

9. Page AM, Collins JN, Britt LD. An incarcerated femoral hernia containing a Meckel's diverticulum. Am Surg. 2009;75(3):263-265.

10. Wollgast GF, Hilz JM. Littre's hernia: strangulation of Meckel's diverticulum in a femoral hernia and an inguinal hernia. Am Surg. 1962;28:741-744.

11. Wong BS, Larson DW, Smyrk TC, Oxentenko AS. Perforated Meckel's diverticulum presenting with combined bowel and urinary obstruction and mimicking Crohn's disease: a case report. J Medical Case Reports. 2010;4:264-269.

12. Yang JF, Sun LM, Wang XF, Dai N. Massive gastrointestinal bleeding from Meckel diverticulum with ectopic pancreatic tissue. Chin Med J (Eng). 2011;124(4):631-633.

13. Oglevie SB, Smith DC, Gardiner GA. Angiographic demonstration of bleeding in an unusually located Meckel's diverticulum simulating colonic bleeding. Cardiovasc Intervent Radiol. 1989;12(4):210-212.

14. Thirunavukarasu P, Sathaiah M, Sukumar S, et al. Meckel's diverticulum - a high-risk region for malignancy in the ileum. Insights from a population-based epidemiological study and implications in surgical management. Ann Surg. 2011;253(2):223-230.

15. Cullen JJ, Keith KA, Moir CR, Hodge DO, Zinsmeister AR, Melton LJ. Surgical management of Meckel's diverticulum. An epidemiologic, population-based study. Ann Surg. 1994;220(4):564-569. 
16. Sharma RK, Jain VK. Emergency surgery for Meckel's diverticulum. World J Emerg Surg. 2008;3:27.

17. Whang EE, Ashley SW, Zinner MJ. Small intestine. In: Brunicardi FC, editor. Schwartz's Principles of Surgery, 8th ed. New York: McGrawHill; 2005:1043-1044.

18. Prasad TR, Chui CH, Jacobsen AS. Laproscopic-assisted resection of Meckel's diverticulum in children. JSLS. 2006;10(3):310-316.

19. Pollak R. Adjunctive procedure in intestinal surgery. In: Fischer JE; Bland KI, editors. Mastery of Surgery, 5th ed. Philedelphia: Lippincott Williams \& Wilkins; 2007:1392-1393.

20. Christie A. Meckel's diverticulum: a pathologic study of sixty-three cases. Am J Dis Child. 1931;42:544-553.

21. Edmonson JM. Johann Friedrich Meckel the younger: Meckel's diverticulum. Gastrointest Endosc. 2001;54(1):19A-20A.

22. Moore KL, Persaud TVN, Torchia MG. Before we are Born: Essentials of Embryology and Birth Defects, 8th ed. Philadelphia: Saunders; 2012.

23. Limas C, Seretis K, Soultanidis C, Anagnostoulis S. Axial torsion and gangrene of a giant Meckel's diverticulum. J Gastrointestin Liver Dis. 2006;15(1):67-68.

24. Schoenwolf GC, Bleyl SB, Brauer PR, Francis-West PH. Larsen's Human Embryology, 4th ed. Philadelphia: Churchill Livingstone/ Elsevier; 2009.

25. Stone PA, Hofeldt MJ, Campbell JE, Vedula G, DeLuca JA, Flaherty SK. Meckel diverticulum: ten-year experience in adults. South Med J. 2004;97(11):1038-1041.

26. Lin S, Suhocki PV, Ludwig KA, Shetzline MA. Gastrointestinal bleeding in adult patients with Meckel's diverticulum: the role of technetium 99m pertechnetate scan. South Med J. 2002;95(11):1338-1341.

27. Sagar J, Kumar V, Shah DK. Meckel's diverticulum: a systematic review. J R Soc Med. 2006;99(10):501-505.

28. Chu UB, Beals DA, Schwartz RW. Laparoscopic management of Meckel's diverticulum. Curr Surg. 2001;58(5):458-461.

29. Fagenholz PJ, de Moya MA. Laparoscopic treatment of bowel obstruction due to a bezoar in a Meckel's diverticulum. JSLS. 2001;15(4):562-564.

30. Elsayes KM, Menias CO, Harvin HJ, Francis IR. Imaging manifestations of Meckel's diverticulum. AJR Am J Roentgenol. 2007;189(1); $81-88$.

31. Stone PA, Hofeldt MJ, Lohan JA, Kessel JW, Flaherty SK. A rare case of massive gastrointestinal hemorrhage caused by Meckel's diverticulum in a 53-year-old man. WV Med J. 2005;101(2):64-66.

32. Roessel CW. Perforation of Meckel's diverticulum by foreign body: case report and review of the literature. Ann Surg. 1962;156: 972-975.

33. Canelas AL, Neto AN, Rodrigues AL, Meguins LC, Rolo DF, Lobato MF. Perforation of Meckel's diverticulum by a chicken bone mimicking acute appendicitis. Case report. G Chir. 2009;30(11-12):476-478.

34. Kazemi K, Jalaeian H, Fattahi MR, Hosseini SV, Shafiee M, Roshan N. Ruptured Meckel's mesodiverticulum and Meckel's diverticulum following blunt abdominal trauma. Med Princ Pract. 2008;17(2):161-163.

35. Greenspan L, Abramovitch A, Tomarken J, Cohen Z. Perforation of a Meckel's diverticulum by a foreign body. Can J Surg. 1983;26(2): 184-185.

36. Park JJ, Wolff BG, Tollefson MK, Walsh EE, Larson DR. Meckel's diverticulum: the Mayo Clinic experience with 1476 patients (1950-2002). Ann Surg. 2005;241(3):529-533.

37. De Mulder RM, Verschave JG. Perforated leiomyosarcoma of Meckel's diverticulum. Case report. Eur J Surg. 1991;157(1):69-70.

38. Karabulut R, Sonmez K, Turkyilmaz Z, et al. Negative appendectomy experience in children. Ir J Med Sci. 2011;180(1):55-58.

39. Enç F, Yorulmaz E, Melikoğlu L, et al. A case of Meckel's diverticulitis treated on the assumption of Crohn's disease. Turk J Gastroentrol. 2010;21(2):175-178.

40. Baum RK, Olch IY. Meckel's diverticulum in a femoral hernia. Calif Med. 1958;88(5):386-388.
41. Sparburg M. Chronic iron deficiency anemia due to Meckel's diverticulm. Am J Dis Child. 1967;113(2):286-287.

42. Reddin A, Rosenbaum RC. False positive Meckel's scan caused by carcinoid tumors of the small bowel. Clin Nucl Med. 1987;12(2):128-130.

43. Tulchinsky M. Meckel's scan: pitfall in patients with active small bowel bleeding. Clin Nucl Med. 2006;31(12):814-816.

44. Koh HC, Page B, Black C, Brown I, Ballantyne S, Galloway DJ. Ectopic pancreatic-type malignancy presenting in a Meckel's diverticulum: a case report and review of the literature. World J Surg Oncol. 2009;7:54.

45. James GK, Berean KW, Nagy AG, Owen DA. Inverted Meckel's diverticulum: an entity simulating an ileal polyp. Am J Gastroenterol. 1998;93(9):1554-1555.

46. Shelton JH, Newsome TW, Ford KL III, Hamilton JK. Inverted Meckel's diverticulum presenting as iron deficiency anemia. Endoscopy. 2006;38 Suppl 2:S93-S94.

47. Steinwald PM, Trachiotis GD, Tannebaum IR. Intussusception in an adult secondary to an inverted Meckel's diverticulum. Am Surg. 1996;62(11):889-894.

48. Pantongrag-Brown L, Levine MS, Elsayed AM, Buetow PC, Agrons GA, Buck JL. Inverted Meckel's diverticulum: clinical, radiologic, and pathologic findings. Radiology. 1996;199(3):693-696.

49. Tobias R, Mee AS, Dent DM, Fataar S. Meckel's diverticulum causing iron deficiency anaemia in adulthood. A case report. $S$ Afr Med $J$. 1982;62(2):68-69.

50. Al-Onaizi I, Al-Awadi F, Al-Dawood AL. Iron deficiency anaemia: an unusual complication of Meckel's diverticulum. Med Princ Pract. 2002;11(4):214-217.

51. Arnold C, Marjoniemi V. Islet of Langerhans heterotopia in Meckel's diverticulum. Pathology. 2006;38(5):452-454.

52. Ogata H, Oshio T, Ishibashi H, Takano S, Yagi M. Heterotopic pancreas in children: review of the literature and report of 12 cases. Pediatr Surg Int. 2008;24(3):271-275.

53. Anderson DJ. Carcinoid tumor in Meckel's diverticulum: laparoscopic treatment and review of the literature. J Am Osteopath Assoc. 2000;100(7):432-434.

54. Moyana TN. Carcinoid tumors arising from Meckel's diverticulum: A clinical, morphologic, and immunohistochemical study. Am J Clin Pathol. 1989;91(1):52-56.

55. Nies C, Zielke A, Hasse C, Rüschoff J, Rothmund M. Carcinoid tumors of Meckel's diverticula: Report of two cases and review of the literature. Dis Colon Rectum. 1992;35(6):589-596.

56. Shebani KO, Souba WW, Finkelstein DM, et al. Prognosis and survival in patients with gastrointestinal tract carcinoid tumors. Ann Surg. 1999;229(6):815-821.

57. Kusumoto H, Yoshitake H, Mochida K, Kumashiro R, Sano C, Inutsuka S. Adenocarcinoma in Meckel's diverticulum: report of a case and review of 30 cases in the English and Japanese literature. Am J Gastroenterol. 1992;87(7):910-913.

58. Lippe P, Berardi R, Latini L, Bracci R, Cellerino R. Severe prognosis of signet-ring cell adenocarcinoma occurring in Meckel's diverticulum. Ann Oncol. 2001;12(2):277.

59. Parente F, Anderloni A, Zerbi P, et al. Intermittent small-bowel obstruction caused by gastric adenocarcinoma in a Meckel's diverticulum. Gastrointest Endosc. 2005;61(1):180-183.

60. Rieber JM, Weinshel EH, Nguyen T, Sidhu GS, Bini EJ. Synchronous gastric adenocarcinomas in a patient with Meckel's diverticulum. J Clin Gastroenterol. 2001;33(1):78-80.

61. Cates JM, Williams TL, Suriawinata AA. Intraductal papillary mucinous adenoma that arises from pancreatic heterotopia within a Meckel diverticulum. Arch Pathol Lab Med. 2005;129(3):e67-e69.

62. Lorusso R, Forte A, Urbano V, et al. I tumori stromali del tenue a localizzazione meckeliana. A proposito di un'osservazione clinica [Small bowel stromal tumors in a "Meckelian" location. About a clinical observation]. Ann Ital Chir. 2003;74(6):707-711. Italian.

63. Khoury MG, Aulicino MR. Gastrointestinal stromal tumor (GIST) presenting in a Meckel's diverticulum. Abdom Imaging. 2007;32(1):78-80. 
64. Shimizu N, Kuramoto S, Mimura T, et al. Leiomyosarcoma originating in Meckel's diverticulum: report of a case and a review of 59 cases in the English literature. Surg Today. 1997;27(6):546-549.

65. Beyrouti MI, Ben Amar M, Beyrouti R, et al. Complications du diverticule de Meckel, a propos de 42 cas [Complications of Meckel's diverticulum. Report of 42 cases]. Tunis Med. 2009;87(4):253-256. French.

66. Kim J, Kim YS, Chun HJ, Hyun JH, Cho MY, Suh SO. Laparoscopyassisted exploration of obscure gastrointestinal bleeding after capsule endoscopy: the Korean experience. J Laparoendosc Adv Surg Tech A. 2005; 15(4):365-373

67. Krespis EN, Sakorafas GH. Partial intestinal obstruction caused by a lipoma within a Meckel's diverticulum. Dig Liver Dis. 2006;38(5):358-359.

68. Yao JL, Zhou H, Roche K, Bangaru BS, Ginsburg H, Greco MA. Adenomyoma arising in a Meckel diverticulum: case report and review of the literature. Pediatr Dev Pathol. 2000;3(5):497-500.

69. Minimo C, Talerman A. Villous adenoma arising in Meckel's diverticulum. J Clin Pathol. 1998;51(6):485-486.

70. Mudatsakis N, Paraskakis S, Lashitiotakis K, Andreadakis E, Karatsis P. Acute appendicitis and carcinoid tumor in Meckel's diverticulum. Three pathologies in one: a case report. Tech Coloproctol. 2011; 15 Suppl 1:S83-S85.

71. Payne-James JJ, Law NW, Watkins RM. Carcinoid tumour arising in a Meckel's diverticulum. Postgrad Med J. 1985;61(721):1009-1011.

72. Schwartz S, Shires TJ, Spencer F. Principles of Surgery, 7th ed. New York: McGraw-Hill; 1999

73. Olson CH, Ahmad R, Downs JM. Carcinoid within a Meckel's diverticulum. Am Surg. 2010;76(11):1311-1312.

74. Chandramohan K, Agarwal M, Gurjar G, et al. Gastrointestinal stromal tumour in Meckel's diverticulum. World J Surg Oncol. 2007;5:50-55.
75. Mitchell W, Kaye P, Dhingsa R, Lobo D. Education and imaging Gastrointestinal: a gastrointestinal stromal tumour (GIST) arising in a Meckel's diverticulum. J Gastroenterol Hepatol. 2011;26(2):1812.

76. Chou YH, Tu C, Huang CC, Hsieh MS. A clinically-occult gastrointestinal stromal tumor in a Meckel's diverticulum presenting as hollow organ perforation. Chang Gung Med J. 2011;34(Suppl 6):56-61.

77. Sozen S, Tuna O. A rare case of perforated Meckel's diverticulum presenting as a gastrointestinal stromal tumor. Arch Iran Med. 2012; 15(5):325-327.

78. Summers HG, Loftus EV Jr, Sebo TJ, Durski JM. Appendiceal carcinoid mimicking a Meckel's diverticulum on Tc-99m pertechnetate imaging. Clin Nucl Med. 2010;35(4):277-279.

79. Hod N, Mindlin L, Horne T. "False-negative" Meckel's scan caused by a recent barium study. Clin Nucl Med. 2002;27(1):57-58.

80. Artigas V, Calabuig R, Badia F, Ruis X, Allende L, Jover J. Meckel's diverticulum: value of ectopic tissue. Am Surg. 1986;151(5):631-634.

81. Robijn J, Sebrechts E, Miserez M. Management of incidentally found Meckel's diverticulum a new approach: resection based on a Risk Score. Acta Chir Belg. 2006;106(4):467-470.

82. Mukai M, Takamatsu H, Noguchi H, Fukushige T, Tahara H, Kaji T. Does the external appearance of a Meckel's diverticulum assist in choice of the laparoscopic procedure? Pediatr Surg Int. 2002;18(4):231-233.

83. Varcoe RL, Wong SW, Taylor CF, Newstead GL. Diverticulectomy is inadequate treatment for short Meckel's diverticulum with heterotopic mucosa. ANZ J Surg. 2004;74(10):869-872.
Pediatric Health, Medicine and Therapeutics

\section{Publish your work in this journal}

Pediatric Health, Medicine and Therapeutics is an international, peerreviewed, open access journal publishing original research, reports, editorials, reviews and commentaries. All aspects of health maintenance, preventative measures and disease treatment interventions are addressed within the journal. Practitioners from all disciplines are invited to submit

\section{Dovepress}

their work as well as healthcare researchers and patient support groups. The manuscript management system is completely online and includes a very quick and fair peer-review system. Visit http://www.dovepress.com/ testimonials.php to read real quotes from published authors. 